\title{
A centralised DEA approach to resource reallocation in Spanish airports
}

\author{
Ane Elixabete Ripoll-Zarraga ${ }^{\mathrm{a}}$ and Sebastián Lozano ${ }^{\mathrm{b}}$ \\ a Business Department, Universitat Autònoma de Barcelona (UAB), 08193 Bellaterra, Spain \\ ${ }^{\mathrm{b}}$ Escuela Superior de Ingenieros, University of Seville, Spain
}

* Corresponding author.

E-mail address: ane rz@yahoo.com

\author{
ARTÍCULO PUBLICADO EN \\ Annals of Operations Research (2019) \\ doi: https://doi.org/10.1007/s10479-019-03271-6
}

\begin{abstract}
A centralized data envelopment analysis (DEA) approach optimises the resource usage for all the different units in an organization rather than for each unit separately (conventional DEA). This is particularly relevant for the Spanish airports controlled centrally by the Spanish Airport Authority (AENA) rather than by individual airport managers. In this study, a non-oriented Slack-based inefficiency (SBI) DEA model is used in order to reallocate two transferrable inputs (namely, labour costs and operating costs) between the different airports. Firstly, we apply a conventional (i.e. noncentralized) non-oriented SBI model to identify the inefficient airports. Then, we apply the corresponding centralised DEA model to the inefficient units to maximise the potential improvements (slacks) obtained by reducing the total consumption of the inputs (allowing resource reallocation) and increasing total outputs. The results show how it is feasible to increase the total amount of passengers and cargo as well as the number of aircraft movements without increasing the total amount of inputs, just by reallocating them in an efficient way. Several progressively more relaxed scenarios have been considered, leading to larger total potential efficiency improvements. The model identifies airports that suffer from over-capacity and provide individual targets in each input and output to become more efficient. Sensitivity analysis to outliers or mavericks (i.e. airports with a strong specialisation) has been carried out. The size efficiency of individual airports as well as the overall company has also been studied. The potential efficiency gains and the optimal number of airports in a radical system restructuring have been computed and the optimal size operating point has been determined and compared with the actual inputs and outputs of the existing airports.
\end{abstract}

Keywords: Centralised DEA; Spanish airports; centralised management; Slack-Based Inefficiency (SBI); size efficiency 


\section{Introduction}

Data Envelopment Analysis a non-parametric methodology commonly used to estimate the efficiency of a set of homogenous decision making units (DMUs). The development of a DEA model requires making decisions about several questions such as the orientation, the returns to scale or the appropriate selection of inputs and outputs (Cook et al. 2014). Resource allocation using DEA has been addressed from several perspectives (e.g.Wei et al. 2000; Hadi-Vencheh et al. 2008; Lozano et al. 2004, 2009; Du et al. 2010; Hosseinzadeh et al. 2010; Amirteimoori and Emrouznejad 2012; Fang and Li 2015 , etc.). From an empirical perspective, it is important to critically assess who controls the resources or the production levels. Traditional DEA models optimise separately the resource allocation for each DMU. But this individual optimisation does not correspond to units organised under the same management (Boussofiane et al. 1991; Thanassoulis, 2001; Bogetoft, 2013) or with a budget (Kao, 2000).

Resource allocation is a relevant matter in management. This refers to distributing a limited number of resources (inputs) to different units to meet the overall corporate goals. The units may have different levels of aggregation (departments, divisions, chain, branches, etc.) depending on the level of centralisation. Strong centralised management perspective confronts the flexibility of DMUs' managers to decide freely resources allocation and production transfers. Korhonen and Syrjänen (2004) propose a resource-allocation approach to be used in organizations with a centralized decision-making process. With this same aim, further DEA models have been proposed to analyse units under some form of central management (for example, Lozano and Villa 2004; Varmaz et al. 2013). Lozano and Villa $(2004,2005)$ proposed the centralised resource allocation BCC model (CRA$\mathrm{BCC}$ ). In situations where the units of assessment are controlled by one central authority (parent company, head office, council, regional authority, etc.), certain inputs used are in fact nondiscretionary at the DMU level: the individual unit managers have no control. Centralised DEA has been applied to a range of sectors and degree of management centralisation: vessels (Färe et al. 2000), fast-food restaurants (Gimenez-Garcia et al. 2007) and public services such as hospitals (Li and Ng, 1995), local authorities (Athanassopoulos 1995), recycling municipalities (Lozano et al. 2004), schools (Mar-Molinero et al. 2014) and other services (Asmild et al. 2009). White and Bordoloi (2015) provide a review of DEA-resource and cost allocation models evidencing a relevance of financial and banking studies compared to other industries. The literature review indicates that there are few applications of centralised DEA in transportation, e.g. in ports (Lozano et al. 2011) and human resources allocation in airports (Yu et al.2013). In this paper, a centralised DEA approach is applied to the Spanish airport system. Most of the studies in the Spanish airport system use DEA following the traditional models (e.g. Lozano and Gutierrez 2011a), in some cases considering undesirable outputs (e.g. Lozano and Gutierrez 2011b) using a network DEA approach (e.g. Lozano et al. 2013) or combining DEA with a second stage or a stochastic frontier analysis (see Ripoll-Zarraga and Mar-Molinero 2017 for a review).

DEA-resource allocation approaches can be classified as invariant efficiency (e.g. Yan et al. 2002; Korhonenand Syrjänen, 2004; Amirteimoori, 2006; Hadi-Vencheh et al. 2008) and changeable efficiency after the resource reallocation (e.g. Beasley 2003;Korhonen and Syrjänen 2004; Lozano et al. 2009; Mar-Molinero et al. 2014). In this study, the second approach is considered. Managerial guidance is drawn to reallocate inputs and increase outputs between different airports in order to improve the overall efficiency of the Spanish airport system. It is important to bear on mind that this is possible due to the centralised management of the airports. In order to simplify the model, undesirable outputs are not considered (Ripoll-Zarraga and Mar-Molinero, 2017).

The Spanish airports are government owned and managed through a company named AENAunder an airport-system. The structure of an airport system implies a cross-subsidisation from profitable to non-profitable airports. The strong degree of centralisation is to the extent that AENA applies similar accounting policies such as depreciation. Competition between airports is practically non-existent. Consequently, there are geographical areas with more than one airport in an influence distance (catchment area). Most of the airports have a significant infrastructure for their level of 
traffic. Investments have been made by the Spanish government based on forecasting models resulting in a system with over-capacity and inefficiencies. Additionally, airports' managers cannot decide commercial policies to attract airlines and passengers. Overall the centralised management makes the network unprofitable. Under this degree of centralisation the question to address is if resources under-used by an airport could be transferred to other airports increasing the overall efficiency of the system. The resource allocation for discretionary inputs (or production) could be optimised across the network. In the case of the Spanish airports the centralised DEA model is particularly useful since the optimisation of resources utilisation applies for all the airports as a whole rather than optimising each airport separately. Hence, the aim of this paper is to use existing centralised DEA and size efficiency approaches to measure the potential gains from removing technical inefficiency in each individual airport, reallocate inputs within the system and restructure the whole Spanish airport system. The proposed approach provides a wealth of information on the current technical and size efficiency status of the different airports and of the company as a whole, measuring the potential efficiency gains under different improvement scenarios and providing specific input and targets as well as an optimal size input-output vector.

To the best of our knowledge, this is the first time that a centralized DEA approach is applied in this context. Since there are many DEA studies of airports, at both the national and regional level (e.g.Gutierrez and Lozano 2016), using conventional and network DEA approaches (e.g.Lozano and Gutierrez 2011a, Lozano et al. 2013) and sometimes considering undesirable outputs (e.g. Lozano and Gutierrez 2011b), a thorough literature review of this type of DEA applications is beyond the scope of the paper. However, it may be interesting to analyse the variables commonly considered in the efficiency assessment of airports. Thus, Table 1 shows a representative sample of the inputs and outputs considered in different studies (see Gutierrez and Lozano 2016 for a more thorough literature survey of inputs and outputs in airport DEA applications).

Table 1: Input and output variables considered in different DEA studies

\begin{tabular}{|c|c|c|c|c|}
\hline Reference & Inputs & Outputs & $\begin{array}{c}\text { Undesirable } \\
\text { outputs }\end{array}$ & Exogenous variables \\
\hline $\begin{array}{l}\text { Gillen and Lall } \\
\text { (1997) }\end{array}$ & $\begin{array}{l}\text { runways, boarding gates, terminal } \\
\text { area, employees, baggage belts, } \\
\text { public parking slots }\end{array}$ & passengers, cargo & - & - \\
\hline $\begin{array}{l}\text { Gillen and Lall } \\
\text { (1997) }\end{array}$ & $\begin{array}{l}\text { runways, runway area, airport } \\
\text { area, employees }\end{array}$ & $\begin{array}{l}\text { air carrier movements, } \\
\text { commuter movements }\end{array}$ & - & - \\
\hline Sarkis (2000) & $\begin{array}{l}\text { Number of runways, boarding } \\
\text { gates, employees, and operating } \\
\text { costs }\end{array}$ & $\begin{array}{l}\text { Passengers, cargo, aircraft } \\
\text { movements, movements } \\
\text { (general aviation), } \\
\text { operating revenues }\end{array}$ & - & - \\
\hline $\begin{array}{l}\text { Martin and Roman } \\
(2001,2006)\end{array}$ & $\begin{array}{l}\text { Labour costs, capital costs, } \\
\text { materials cost }\end{array}$ & $\begin{array}{l}\text { Passengers, aircraft } \\
\text { movements, cargo }\end{array}$ & - & - \\
\hline $\begin{array}{l}\text { Abbot and Wu } \\
(2002)\end{array}$ & $\begin{array}{l}\text { Runway length, number of } \\
\text { employees, capital stock }\end{array}$ & Passengers, cargo & - & $\begin{array}{l}\text { Aircraft standing area, } \\
\text { rate of return, capital } \\
\text { labour ratio, total asset } \\
\text { growth rate, ownership } \\
\text { (dummy), year (dummy) }\end{array}$ \\
\hline Pels et al. (2003) & $\begin{array}{l}\text { Terminal size, number of aircraft } \\
\text { parking places (at the terminal } \\
\text { and remote), check-in desks, } \\
\text { baggage belts }\end{array}$ & $\begin{array}{l}\text { Passengers, aircraft } \\
\text { movements }\end{array}$ & - & $\begin{array}{l}\text { Slot coordinated } \\
\text { (dummy), time } \\
\text { restrictions (dummy), } \\
\text { airlines' load factor, } \\
\text { time (dummy) }\end{array}$ \\
\hline
\end{tabular}


Passengers, aircraft movements

Population (county))
Passengers, number of planes, cargo, aeronautical revenues, handling revenues, commercial

revenues
Barros and Dieke Labour costs, capital invested, (2007)
Work load units (WLU) ${ }^{1}$, rotation of capital, privatisation (dummy)
Pathomsiri et al. (2008) Number of runways, runway and land areas
Passengers, cargo, \% nondelayed flights
$\%$ delayed flights, minutes of delays
Load factor

(PAX/movement), cargo load factor (Tone cargo/movement), \% general aviation movements, \% international PAX, movement market share
Lozano and

Gutierrez (2011b)
Runway area, apron capacity, boarding gates, baggage belts, check-in desks
Passengers, aircraft movements, cargo
$\%$ delayed flights, average delay of delayed flights
Work load units (WLU), $\mathrm{x} \%$ passengers handled by low-cost carriers, $x \%$ cargo relative to the total WLUs
Coto-Millan et al.
Labour costs, capital invested, operational costs
Passengers, aircraft movements, cargo

Ownership structure, hub status
Runway area, apron stands, boarding gates, scheduled routes, airlines
Passengers, aircraft

movements, cargo

This paper is organised as follows. Section 2 presents the conventional non-centralised slackbased-inefficiency (SBI) approaches well as the conventional radial centralised DEA approach. Section 3 formulates and discusses the specific centralised SBI approach used in this paper. Section 4 presents the data and the analysis of results. Section 5 discusses the size inefficiency of individual airports as well as of the whole Spanish airport system. Finally, Section 6 summarizes and concludes.

\section{Relevant DEA approaches}

\subsection{Non-centralised SBI approach}

The SBI DEA approach was first proposed by Fukuyama and Weber (2009) and its key feature is that it uses as objective function the maximization of the input and output slacks normalized using the components of a given directional vector $g=\left(g_{i}^{x}, g_{k}^{y}\right)$ The flexibility of being able to choose the slacks normalization constants as well as the fact of not requiring the linearization of the model (unlike the slacks-based measure of Tone, 2001) makes this approach very attractive and easy to use. It can also handle undesirable outputs (e.g. Gutierrez et al. 2017) and it can be used in network DEA contexts (e.g. Fukuyama and Weber 2010; Lozano 2016, 2017).

\footnotetext{
${ }^{1}$ One Work Load Unit (WLU) is equivalent to one passenger or $100 \mathrm{~kg}$ of cargo.
} 
Let $j$ index the $n$ DMUs of the system $(j=1,2, \ldots, n)$. Let $I$ be the set of inputs and $x_{i j}$ the consumption of input $i$ by DMU $j$. Analogously, let $O$ be the set of outputs and $y_{k \mathrm{j}}$ the production of output $k$ by DMU $j$. Let $o$ be the DMU to be projected and $s_{i o}^{x}$ and $s_{k o}^{y}$ the input and output slacks, respectively, of $\mathrm{DMU} o$, i.e. the corresponding amounts that each input can be reduced and each output can be increased. The conventional non-centralised SBI model can be formulated as

$\operatorname{Max} \sum_{i \in I} \frac{s_{i o}^{x}}{g_{i}^{x}}+\sum_{k \in O} \frac{s_{k o}^{y}}{g_{k}^{y}}$

s.t.

$\sum_{j=1}^{n} \lambda_{j} x_{i j}=x_{i o}-s_{i o}^{x} \quad \forall i \in I$

$\sum_{j=1}^{n} \lambda_{j} y_{k j}=y_{k o}+s_{k o}^{y} \quad \forall k \in O$

$\sum_{j=1}^{n} \lambda_{j}=1$

$\lambda_{j} \geq 0 \forall j \quad s_{i o}^{x} \geq 0 \forall i \in I \quad s_{k o}^{y} \geq 0 \forall k \in O$

\subsection{Radial centralised DEA approach}

Lozano and Villa (2004) presented two input-oriented centralised DEA resource allocation approaches, one radial and another non-radial. The radial model (labelled CRA-BCC) maximizes the radial increase of the total outputs that can be achieved without increasing the total inputs. The input-oriented CRA-BCC model can be formulated as

$\operatorname{Min} \theta$

s.t.

$\sum_{r=1}^{n} \sum_{j=1}^{n} \lambda_{j r} x_{i j} \leq \theta \sum_{r=1}^{n} x_{i r} \quad \forall i \in I$

$\sum_{r=1}^{n} \sum_{j=1}^{n} \lambda_{j r} y_{k j} \geq \sum_{r=1}^{n} y_{k r} \quad \forall k \in O$

$\sum_{j=1}^{n} \lambda_{j r}=1 \quad \forall r$

$\lambda_{j r} \geq 0 \quad \forall j \forall r \quad \theta$ free

Note that a key feature of centralised DEA approaches is that all the DMUs are projected simultaneously so that a centralised (i.e. system-wide) criterion can be used to determine the target of each DMU and the resource reallocation among the DMUs. Thus, in order to project each DMU its 
own set of intensity variables lambda is required. The constraints of the model, apart from the convexity constraints that indicate that Variables Returns to Scale (VRS) is assumed, guarantee that the total output level is maintained and that the total inputs are reduced uniformly (i.e. equiproportionally). The objective function aims at maximizing that radial input reduction. Note that, as in all radial DEA approaches, phase II is required to exhaust all possible input and output slacks so that the targets are guaranteed to lie on the efficient frontier.

Mar-Molinero et al. (2014) developed a simplified version of the above CRA-BCC model where the most efficient units are "cloned" system-wide. Also, Asmild et al. (2009) extended the above model by suggesting changes only for the inefficient units, maintaining the efficient DMU intact. They labelled their approach CRAI-BCC. Denoting by $\mathrm{E}$ the set of efficient DMUs the input-oriented CRAIBCC model can be formulated as

\section{$\operatorname{Min} \theta$}

s.t.

$$
\begin{aligned}
& \sum_{r \notin E} \sum_{j \in E} \lambda_{j r} x_{i j} \leq \theta \sum_{r \notin E} x_{i r} \quad \forall i \in I \\
& \sum_{r \notin E} \sum_{j \in E} \lambda_{j r} y_{k j} \geq \sum_{r \notin E} y_{k r} \quad \forall k \in O \\
& \sum_{j \in E} \lambda_{j r}=1 \quad \forall r \notin E \\
& \lambda_{j r} \geq 0 \quad \forall j \in E \forall r \notin E \quad \theta \text { free }
\end{aligned}
$$

Note that this model uses a radial and oriented metric while, in this study, a non-radial and nonoriented approach is used.

\section{Proposed SBI centralised DEA approach}

Since all the airports are managed by the same company (AENA), the assumption made in this paper assumes a degree of flexibility regarding reallocation of inputs and/or transfer outputs among the different DMUs (e.g. Athanassopoulos 1995; Lozano and Villa 2004). Centralised DEA can also consider certain inflexibility as regards resource reallocation (e.g. Nesterenko and Zelenyuk 2007; Asmild et al. 2009). In particular, certain inputs may not be transferable and therefore cannot be reallocated. The advantage of using centralised DEA is that it projects all the DMUs simultaneously in one single linear programming problem. The common aim is to reduce the total input consumption of the system and/or globally increase the production of all the outputs. Note that some resources maybe transferred from some DMUs to others that, consequently, will be able to increase their outputs.

The proposed centralised DEA approach uses the idea of Asmild et al. (2009) of maintaining the efficient DMUs as they are and jointly project only the inefficient DMUs. This means that we have to carry out two steps. Step I identifies the efficient and inefficient units. Although for this step a conventional BBC model (Banker at al. 1984) could be used, in our case, for convenience and consistency, the non-centralised SBI model of section 2.1. is used. In Step II a centralised projection of the inefficient units is carried out so as to maximize an SBI measure involving the total input and output slacks. Note that the reallocation of inputs is possible only for transferable ones, but not for 
inputs such as capital. In particular, in this study, depreciation is one such non-discretionary and non-transferable input. Another feature of the proposed model that neither the CRA-BCC approach of Lozano and Villa (2004) nor the CRAI-BCC approach of Asmild and Pastor (2009) considers is to impose constraints that guarantee that none of the DMUs reduce their outputs. That is a realistic assumption (otherwise the DMU managers may not concur with the proposed approach) and one perfectly consistent with the aim of increasing the total system outputs. The model also provides a peer group for each inefficient unit. $\left\{j \in E: \lambda_{j r}>0\right\}$. The value of the lambda variables provides clues about the relevance of each specific efficient DMU as benchmark (i.e. reference unit) for each inefficient DMU. Larger values indicate more importance of the efficient DMU as reference unit for the corresponding inefficient DMU.

Let $I^{D}$ and $I^{N D}$ be the subsets of discretionary and non-discretionary inputs, respectively. For each discretionary input $i$ let $s_{i o}^{x}$ represent the reduction of that input that the DMU $o$ can achieve and let $s_{k o}^{y}$ represent the increase achievable for each output $k$ by that DMU. Let us assume that the components of the directional vector are the sum of the corresponding input or output for the whole system, i.e. the sum of the observed value for the different DMUs. Those amounts will be the amounts used to normalize the corresponding input and output slacks, i.e.

$$
\begin{aligned}
& g_{i}^{x}=\sum_{r=1}^{n} x_{i r} \quad \forall i \in I^{D} \\
& g_{k}^{y}=\sum_{r=1}^{n} y_{k r} \quad \forall k \in O
\end{aligned}
$$

As indicated in Section 2.1, the SBI model has attractive features that make it useful and appropriate for this application. Thus, it leads to a simple LP formulation whose objective function has an intuitive interpretation as the sum of the normalized input and output slacks. Because the same normalization coefficients for the individual DEA and for the centralized DEA models are used, the aggregation of the slacks of the individual DEA models is consistent and meaningful as regards the comparison with the slacks of the centralized DEA model. On the other hand, the normalization coefficients are such that the aggregate normalized slacks correspond to the total relative system improvement of that variable, i.e. the percentage margin for improvement with respect to the observed value. Same as in the directional distance function (DDF) approach in Peyrache (2013, 2015) these normalization coefficients represent the numeraire in terms of which the inefficiency components are measured. Also, although an unweighted averaging of the normalized slacks is used in the models below, the proposed approach can be easily modified to incorporate the centralized decision maker preference structure, weighing the improvement of certain variables more than others so that the aims of the analysis and the results are aligned with the organization's strategic objectives.

The non-centralised SBI DEA model used in Step I can be formulated as

$$
S B I_{o}=\operatorname{Max} \frac{1}{\left|I^{D}\right|+|O|} \cdot\left(\sum_{i \in I^{D}} \frac{s_{i o}^{x}}{g_{i}^{x}}+\sum_{k \in O} \frac{s_{k o}^{y}}{g_{k}^{y}}\right)
$$

s.t.

$$
\sum_{j=1}^{n} \lambda_{j} x_{i j}=x_{i o}-s_{i o}^{x} \quad \forall i \in I^{D}
$$




$$
\begin{aligned}
& \sum_{j=1}^{n} \lambda_{j} x_{i j} \leq x_{i o} \quad \forall i \in I^{N D} \\
& \sum_{j=1}^{n} \lambda_{j} y_{k j}=y_{k o}+s_{k o}^{y} \quad \forall k \in O \\
& \sum_{j=1}^{n} \lambda_{j}=1 \\
& \lambda_{j} \geq 0 \quad \forall j \quad s_{i o}^{x} \geq 0 \quad \forall i \in I^{D} \quad s_{k o}^{y} \geq 0 \quad \forall k \in O
\end{aligned}
$$

Note that when one or more input or output slacks is greater than zero then $S B I_{O}>0$ and then $\mathrm{DMU} o$ is not efficient.Let be $E^{c}=\left\{r: S B I_{r}>0\right\}$ and $E=\left\{j: S B I_{j}=0\right\}$ the sets of inefficient and efficient DMUs, respectively. The DMU $r$ is projected using a convex combination of the observed DMUs. The vector of variables $\lambda_{j}$ are the coefficients of this linear combination.

Note that the model does not include in the objective function slack variables for the nondiscretionary inputs as no changes are allowed for those variables in the short-term. The corresponding constraint only imposes that the target reference unit does not have a value greater than that of DMU $o$.

For Step II the following centralised SBI DEA model is solved

$$
S B I=\operatorname{Max} \frac{1}{\left|I^{D}\right|+|O|} \cdot\left(\sum_{i \in I^{D}} \frac{S_{i}^{x}}{g_{i}^{x}}+\sum_{k \in O} \frac{S_{k}^{y}}{g_{k}^{y}}\right)
$$

s.t.

$\sum_{j \in E} \lambda_{j r} x_{i j} \leq \hat{x}_{i r} \quad \forall i \in I^{D} \forall r \in E^{c}$

$$
\begin{aligned}
& \sum_{r \in E^{c}} \hat{x}_{i r}=\sum_{r \in E^{c}} x_{i r}-S_{i}^{x} \quad \forall i \in I^{D} \\
& \sum_{j=1}^{n} \lambda_{j r} x_{i j} \leq x_{i r} \quad \forall i \in I^{N D} \forall r \in E^{c} \\
& \sum_{j \in E} \lambda_{j r} y_{k j} \geq \hat{y}_{k r} \geq y_{k r} \quad \forall k \in O \forall r \in E^{c} \\
& \sum_{r \in E^{c}} \hat{y}_{k r}=\sum_{r \in E^{c}} y_{k r}+S_{k}^{y} \quad \forall k \in O
\end{aligned}
$$




$$
\begin{aligned}
& \sum_{j \in E} \lambda_{j r}=1 \quad \forall r \in E^{c} \\
& \lambda_{j r} \geq 0 \quad \forall j \in E \forall r \in E^{c} \quad S_{i}^{x} \geq 0 \quad \forall i \in I^{D} \quad S_{k}^{y} \geq 0 \quad \forall k \in O
\end{aligned}
$$

where $\hat{x}_{i r}$ and $\hat{y}_{k r}$ correspond to the target input and output variables, respectively, of DMU $r$ and $S_{i}^{x}$ and $S_{k}^{y}$ correspond to the system input and output slacks, respectively.

Note that only the inefficient DMUs $\left(r \in E^{c}\right)$ are projected and that the corresponding targets are computed using only the efficient DMUs $(j \in E)$. In order to project each inefficient unit, a lambda column vector is required. This vector contains the coefficients of the linear combination of DMUs that defines the corresponding target for the inefficient unit. Therefore, there are as many lambda vectors as inefficient DMUs $\left(\lambda_{j r}\right)$. Each lambda vector has as many components as efficient DMUs. In other words, the sub-index $r\left(r \in E^{c}\right)$ in $\lambda_{j r}$ refers to the specific DMU $r$ to be projected, and the sub-index $j(j \in E)$ refers to the efficient units integrating the linear combination.

No inefficient DMU reduces its outputs. Their inputs, however, can change in any direction so long as the total input consumption of the system does not increase. Actually, the objective function tries to reduce those total inputs as well as to increase the total outputs. The treatment of the nontransferrable input is different from the other two inputs in the sense that they are fixed and therefore do not change for any inefficient DMU. The corresponding constraint is the same as in the non-centralised DEA approach and follows the conventional way of handling non-discretionary inputs proposed by Banker and Morey (1986).

\section{Results}

The Spanish airport system contains 49 airports, including two heliports and four general aviation airports ${ }^{2}$. The inputs considered are labour costs (excluding air traffic control services), operating costs and depreciation of assets (including the terminals for passengers and cargo). The latter is considered a fixed, non-discretionary (and hence non-transferable) input. In the output side, the variables considered are the number of passengers, air traffic movements, cargo, commercial revenues and percentage of flights on time. All the inputs are transferable except the depreciation of assets as capital cannot be reallocated to other airports. Note that data on the quantity of labour is not available. Therefore, labour costs are used for this technical efficiency assessment. However, as Silva Portela (2014) points out, this is not a problem, provided that the unit prices experienced by the different DMUs are the same, which occurs in this centralized DEA application. Thus, employees' salaries at different airports are the same as they are negotiated between trade unions and the central management of AENA. Financial data were extracted directly from the AENA's annual reports for 2013 except for depreciation of assets since it is highly correlated with operating costs. Following Ashford et al. (1996), the assets were previously classified in airside and landside assets and depreciated accordingly to the standard coefficients used in the airport industry (Ripoll-Zarraga and Mar-Molinero, 2017). Examples of airside assets used are runways, aprons, taxiway, aviation terminals, air traffic control and visualisation systems (beacons). In this study, passengers and cargo terminals, though generally considered landside assets have been both included to compute the value of depreciation. Note that for Madrid Torrejon and Son Bonet no information regarding capital investments was available. Instead of removing them from the sample and losing potential relevant information, the corresponding missing values were substituted by the average value plus 0.3 times the standard deviation of that variable for the rest of airports. Since depreciation is a non-

\footnotetext{
${ }^{2}$ Madrid Torrejon allowed general aviation operations until January $31^{\text {st }}, 2013$
} 
discretionary input, imputing this data should not have a significant influence in the corresponding objective function. Additionally, the fact that both airports have very low civilian traffic ensures that the results are not biased. There were also four missing values for the variable percentage of flights on time. In those cases, the nearest neighbour imputation criterion was used (Ripoll-Zarraga and Mar-Molinero, 2017). Two airports were identified having a similar infrastructure or aeronautical activity (i.e. regarding the level of traffic) as the missing: Son Bonet with $50 \%$ of flights on time becomes the nearest neighbour for Algeciras, Ceuta and Huesca-Pirineos and Sabadell with $56.25 \%$ for Madrid Cuatro Vientos. The statistics of the different variables are shown in Table 2.

Table 2: Summary statistics of the dataset

\begin{tabular}{lccccc}
\hline \multicolumn{1}{c}{ Variable } & Observations & Mean & Standard Dev. & Minimum & Maximum \\
\hline Labour Costs $(€)$ & 49 & $6,113.92$ & $9,082.62$ & 108.12 & $48,934.72$ \\
\hline Operating Costs $(€)$ & 49 & $19,035.00$ & $49,084.02$ & 333.38 & $299,582.10$ \\
\hline Depreciation Airside and & 47 & $3,989.57$ & $9,817.64$ & 27.00 & $65,429.59$ \\
Terminals $(€)$ & 49 & $3,824,594.47$ & $8,105,923.78$ & 273 & $39,735,618$ \\
\hline Passengers & 49 & $36,549.96$ & $64,081.76$ & 476 & $333,056.00$ \\
\hline Air Traffic Movements & 49 & $13,039,859.65$ & $51,368,116.40$ & 0 & $346,602,597.00$ \\
\hline Cargo (t) & 49 & $12,865.38$ & $30,489.78$ & 9.01 & $161,391.76$ \\
\hline Commercial Revenues $(€)$ & 45 & 48.85 & 12.97 & 100.00 & 27.27 \\
\hline Flights on Time $(\%)$ & & & &
\end{tabular}

The results of Step I of the proposed approach indicate that 21 out of the 49 airports are efficient. In terms of size, eight out of the 14 large airports (i.e. with more than 3.5 million passengers) are efficient: Alicante and Barcelona (both located in the Mediterranean corridor); Gran Canaria, Lanzarote and Tenerife South (in the Canary Islands); Ibiza and Palma de Mallorca (in the Balearic Islands); and Madrid (which is a hub). There rest of the efficient airports correspond to one medium size airport (Murcia, also in the Mediterranean corridor) and 12 smaller airports with a range of geographical locations: Albacete, Badajoz, Algeciras, Burgos, Logroño; Vitoria and Zaragoza (both cargo-oriented airports); La Gomera (located in the Canary Islands); and the four general aviation airports (Madrid Cuatro Vientos, Madrid Torrejon, Sabadell, Son Bonet). These results confront previous findings regarding specific geographical locations and frontier airports (Martin and Roman, 2001; Tapiador et al. 2008; Tovar and Martin-Cejas, 2010). On the other hand, cargo-oriented airports such as Vitoria and Zaragoza are clearly efficient (Coto-Millan et al. 2016). Table 3 shows the SBI efficiency scores computed by the non-centralised DEA model used for the Step I to identify the efficient and the inefficient airports. The corresponding input and output changes for the inefficient airports are shown in Table B.1 in Appendix B.

Table 3: SBI efficiency scores computed by non-centralised DEA model used for the Step I

\begin{tabular}{lcllcl}
\hline Airport & SBI Value & $\boldsymbol{E}^{\boldsymbol{c}} ; \boldsymbol{E}$ & Airport & SBI Value & $\boldsymbol{E}^{\boldsymbol{c}} ; \boldsymbol{E}$ \\
\hline A Coruña & 0.008667 & Inefficient & Madrid Barajas & 0 & Efficient \\
Albacete & 0 & Efficient & Madrid CuatroVientos & 0 & Efficient \\
Algeciras & 0 & Efficient & Madrid Torrejon & 0 & Efficient \\
Alicante & 0 & Efficient & Malaga & 0.017004 & Inefficient \\
Almeria & 0.004731 & Inefficient & Melilla & 0.007056 & Inefficient \\
Asturias & 0.008047 & Inefficient & Menorca & 0.015807 & Inefficient \\
Badajoz & 0 & Efficient & Murcia & 0 & Efficient \\
Barcelona & 0 & Efficient & Palma de Mallorca & 0 & Efficient \\
\hline
\end{tabular}




\begin{tabular}{lcllcl}
\hline Bilbao & 0.007372 & Inefficient & Pamplona & 0.010417 & Inefficient \\
\hline Burgos & 0 & Efficient & Reus & 0.009166 & Inefficient \\
\hline Ceuta & 0.000856 & Inefficient & Sabadell & 0 & Efficient \\
\hline Cordoba & 0.002448 & Inefficient & Salamanca & 0.001322 & Inefficient \\
\hline El Hierro & 0.000532 & Inefficient & San Sebastian & 0.001178 & Inefficient \\
\hline Fuerteventura & 0.008925 & Inefficient & Santander & 0.002923 & Inefficient \\
\hline Girona & 0.009149 & Inefficient & Santiago & 0.017136 & Inefficient \\
\hline Gran Canaria & 0 & Efficient & Sevilla & 0.005614 & Inefficient \\
\hline Granada-Jaen & 0.011746 & Inefficient & Son Bonet & 0 & Efficient \\
\hline Huesca-Pirineos & 0.001093 & Inefficient & Tenerife North & 0.007131 & Inefficient \\
\hline Ibiza & 0 & Efficient & Tenerife South & 0 & Efficient \\
\hline Jerez & 0.002550 & Inefficient & Valencia & 0.004733 & Inefficient \\
\hline La Gomera & 0 & Efficient & Valladolid & 0.008476 & Inefficient \\
\hline La Palma & 0.011329 & Inefficient & Vigo & 0.009085 & Inefficient \\
\hline Lanzarote & 0 & Efficient & Vitoria & 0 & Efficient \\
\hline Leon & 0.002478 & Inefficient & Zaragoza & 0 & Efficient \\
\hline Logroño & 0 & Efficient & & & \\
\hline
\end{tabular}

Table 4 shows the input and output changes computed by the proposed centralised DEA model for the inefficient airports. Note that the total reduction in the inputs is minimal. The improvement potential corresponds to the outputs, especially in cargo. In order to achieve an efficient use of the system resources the estimated total slack for that variable is $142 \%$.

Table 4: Input and output slacks computed by the centralised DEA model

\begin{tabular}{lccccccc}
\hline Airports & Labour & Operating & PAX & ATM & Cargo & $\begin{array}{c}\text { Commer. } \\
\text { revenues }\end{array}$ & $\begin{array}{c}\text { \% Flights } \\
\text { on Time }\end{array}$ \\
\hline A Coruña & -622.05 & -515.85 & 0 & 0 & $31,616,593$ & 103.58 & 13.99 \\
\hline Almeria & -953.69 & -126.38 & 0 & $25,474.61$ & $9,254,338$ & 0 & 2.51 \\
\hline Asturias & $-1,098.43$ & -463.91 & 0 & $12,027.49$ & $27,823,556$ & 0 & 0 \\
\hline Bilbao & $1,074.45$ & 81.37 & 744,151 & 0 & $41,206,924$ & 0 & 0 \\
\hline Ceuta & 515.84 & $1,397.17$ & 0 & $26,182.87$ & 74 & 490.46 & 8.82 \\
\hline Cordoba & $1,687.03$ & $1,801.95$ & 279,228 & 0 & $46,185,076$ & 953.57 & 0 \\
\hline El Hierro & -554.21 & -473.38 & 0 & 0 & 0 & 185.47 & 1.96 \\
\hline Fuerteventura & 910.33 & $1,219.50$ & 526,556 & $3,621.64$ & $59,112,762$ & 0 & 7.34 \\
\hline Girona & 627.90 & 478.70 & 0 & 0 & $57,035,845$ & 44.13 & 6.31 \\
\hline Granada-Jaen & -481.93 & $-1,073.51$ & 0 & 0 & $45,561,756$ & 279.59 & 11.84 \\
\hline Huesca-Pirineos & $1,607.51$ & $2,279.76$ & 198,230 & $21,926.04$ & $30,911,998$ & 878.76 & 2.69 \\
\hline Jerez & 105.56 & $2,438.82$ & $1,494,311$ & 0 & $17,547,440$ & $2,483.69$ & 5.30 \\
\hline La Palma & -573.28 & $-1,887.20$ & 0 & 0 & $43,325,930$ & 298.94 & 9.51 \\
\hline Leon & $2,286.84$ & $2,737.80$ & 389,054 & $5,096.26$ & $65,624,703$ & $1,200.90$ & 0 \\
\hline Malaga & -257.64 & $-7,664.84$ & $6,600,689$ & $43,770.40$ & $9,230,005$ & 0 & 0 \\
\hline Melilla & -20.02 & $-1,349.69$ & 0 & 0 & $21,061,007$ & 720.78 & 28.01 \\
\hline Menorca & $-1,682.52$ & -730.17 & 201,098 & 0 & $63,875,029$ & 604.87 & 0.64 \\
\hline & & & & & & & \\
\hline
\end{tabular}




\begin{tabular}{|c|c|c|c|c|c|c|c|}
\hline Pamplona & 415.34 & 152.75 & 139,462 & $11,556.54$ & $46,644,629$ & 528.29 & 3.66 \\
\hline Reus & -401.27 & -554.27 & 0 & 0 & $33,476,822$ & 232.11 & 16.42 \\
\hline Salamanca & 495.74 & -352.28 & 0 & $23,112.88$ & $1,660,336$ & 465.03 & 8.82 \\
\hline San Sebastian & $-1,019.12$ & -747.16 & 10,503 & $1,619.56$ & 465,595 & 0 & 5.41 \\
\hline Santander & -109.68 & 813.07 & 0 & $2,835.45$ & $33,252,937$ & 729.41 & 0 \\
\hline Santiago & $-1,261.65$ & $-2,367.45$ & 267,199 & $2,641.81$ & $64,717,655$ & 0 & 4.34 \\
\hline Sevilla & $-2,327.12$ & -854.75 & 0 & $9,802.41$ & $15,619,738$ & 0 & 0.96 \\
\hline Tenerife North & $1,405.19$ & $4,224.85$ & $2,655,714$ & 0 & $42,925,033$ & $7,084.34$ & 6.04 \\
\hline Valencia & 622.56 & $3,904.49$ & $2,642,612$ & 0 & $41,862,022$ & $1,789.98$ & 0.66 \\
\hline Valladolid & 118.54 & $-1,571.07$ & 0 & $6,105.19$ & $29,903,394$ & 373.66 & 20.65 \\
\hline Vigo & -864.46 & -798.32 & 0 & $13,459.53$ & $28,030,354$ & 0 & 16.46 \\
\hline $\begin{array}{r}\text { Sum } \\
\text { (\%) }\end{array}$ & $\begin{array}{l}-354.24 \\
(0.12 \%)\end{array}$ & $\begin{array}{c}-0.02 \\
(0.00 \%)\end{array}$ & $\begin{array}{c}16,148,808 \\
(8.62 \%)\end{array}$ & $\begin{array}{c}209,232.69 \\
(11.68 \%)\end{array}$ & $\begin{array}{c}907,931,552 \\
(142.10 \%)\end{array}$ & $\begin{array}{c}19,447.59 \\
(3.8 \%)\end{array}$ & $\begin{array}{c}2.24^{\mathrm{a}} \\
(5.06 \%)\end{array}$ \\
\hline
\end{tabular}

${ }^{a}$ Weighted average

Malaga suffers from a significant over-capacity. The new terminal was opened in March 2010 with a forecast of 30 million passengers, but in 2016 traffic still remains at 16.7 million. The infrastructure is underused for operating activities but consumes maintenance services. This is confirmed by the computed slacks in passengers $(+6,600,689)$ and aircraft movements $(+43,770)$ to contribute to the overall efficiency of the system ${ }^{3}$.

There are 15 airports that must increase their operations (aircraft movements). With the exception of Malaga, these are mainly small airports: Ceuta $(+26,182.87)$; Almeria $(+25,474.61)$; Salamanca $(+23,112.88)$; Huesca-Pirineos $(+21,926.04)$; Vigo $(+13,459.53)$ and Pamplona $(+11,556.54)$. Note that this is independent of the slacks in the number of passengers. In fact, some of these airports are not required to increase their number of passengers at all. Consequently, the small airports are inefficient mainly due to their reduced number of aircraft movements more than their number of passengers.

The positive/negative value of the operating costs slacks of some airports indicates that they need to increase/decrease their budget. Thus, Malaga is the airport that should reduce its operating costs the most $(-7,664.84)$. Compared to Tenerife North, which may increase its operating costs the most $(+4,224.85)$. Other airports which may significantly increase their operating costs are Valencia $(+3,904.49)$; Jerez $(+2,438.82)$; Leon $(+2,737.79)$ and Huesca-Pirineos $(+2,279.76)$. For these airports, their current budget may be limiting their output potential. Examples of airports required to reduce their operating costs are Santiago (-2,367.45); La Palma (-1,887.20); Valladolid $(-1,571.07)$; and Granada $(-1,073.51)$. In general, these airports are too expensive to run at their current operating levels.

Fifteen airports require reducing their labour costs, suggesting that most of the airports have human resources over-capacity to generate traffic. Thus, the situation convergences to that studied in $\mathrm{Yu}$ et al. (2013) in which different human resources reallocation policies of Taiwan airports allowed increasing the overall traffic. Sevilla $(-2,327.12)$ has the highest reduction requirement for labour costs. Apart from Sevilla and Bilbao $(+1,074.45)$ the rest of the airports with significant changes in labour are medium and small airports.

Two large airports, namely Tenerife North and Valencia, are required to significantly increase their level of passengers $(+2,655,714 ;+2,642,612$, respectively), but not the labour costs $(+1,405$; +622, respectively). In these cases, it seems that labour and airport infrastructures are used efficiently to generate aircraft movements (with small punctuality slacks) but without enough passengers or cargo.

\footnotetext{
${ }^{3}$ Additionally, both values correspond to the maximum increases for the whole set of airports.
} 
Overall most of the airports are operating at adequate levels of passengers and aircraft movement (13 to 15 inefficient units require increases), but not for cargo, where 27 airports should increase the amount of cargo handling. These results confirm that airports have enough traffic in relation with their capacity (infrastructure) but that it is essential to enhance the commercial aspect of the airports in order to attract passengers and, above all, cargo activities. Some inefficient airports should re-consider the cargo activities altogether in order to enhance the efficiency of the airport system. On the other hand, small airports, such as El Hierro or Ceuta, may focus on civilian transport rather than cargo, ensuring in any case the connectivity of these peripheral regions. Note that the proposed approach uses a non-oriented approach that basically centres on reallocating the inputs (and removing technical inefficiency, of course). Actually, the constraint that each airport cannot reduce its outputs, which has been imposed to facilitate implementation and reduce possible objections of the airport managers, limits the number of output transfers between the airports. As the results show, there is ample slack in the cargo variable, which means that it should be possible to transfer additional cargo to under-utilized airports. In any case, the proposed approach increases the cargo target for many airports, an increase that may come from two sources: new business originating at that airport and cargo redirected from other, saturated airports.

Congestion seems to be a generalised problem since most of the inefficient airports need to increase the percentage of flights on time. In fact, the average percentage of flights on time for the overall system (excluding the four missing data) is just $48.85 \%$. Melilla, although being the airport with more punctuality slack of the system $(+28.01 \%)$, does not, however, require changing the number of passengers or movements. Usually, the smaller the punctuality slack, the higher the slack in aircraft movements. Thus, Almeria requires increasing the percentage of flights on time $+2.51 \%$ and the number of aircraft movements $+25,474.61$. For Huesca-Pirineos, the corresponding figures are $+2.69 \%$ and $+21,926.04$, and for Pamplona $+3.66 \%$ and $+11,556.54$. This does not apply to Ceuta $(+8.82 \%$ and $+26,182.87)$ and Salamanca $(+8.82 \%$ and $+23,112.88)$ with a similar behaviour between them but different from the stated airports. Conversely, the larger the punctuality slacks, the smaller the aircraft movement slack. Thus La Palma $(+9.51 \%)$, Granada $(11.84 \%)$, A Coruña $(+13.99 \%)$, Reus $(+16.42 \%)$ and Melilla $(+28.01 \%)$ with significant punctuality slacks, but do not require increases in the number of movements and passengers. These results suggest that some airports must focus more on reducing delays and becoming punctual than on increasing other outputs such as aircraft movements. At the same time, airports with no congestion problems will require more increments in operations to become more efficient. The airport size seems not to determine the punctuality, suggesting that the slots' current distribution is not a restriction to be efficient.

Since commercial policies such as the quality of the service provided or the price are decided centrally (by AENA) rather than by individual managers, the non-existent competition goes in detriment of generating more traffic (new airlines and routes). As regards commercial revenues, a large number of inefficient airports require increasing them. There is no correlation between the size of airports and the increase needed although Tenerife North clearly shows a high dependency of this type of income in comparison with aeronautical revenues. Diversification towards commercial activities is associated with privatisation processes (Humphreys, 1999). Despite AENA being government-owned at that time, it did not receive any subsidies from the government. Consequently, the Spanish airports have to engage in commercial activities as an alternative source of income (Ripoll-Zarraga et al. 2017). A strong centralised management seems not to help in increasing the aeronautical aspect of airports unless airports can compete to attract passengers and airlines.

The analysis of peer group of each inefficient DMU helps identifying the efficient units the inefficient units should use as best practice reference to achieve the computed targets (see Table B.2 in Appendix B). There are only nine efficient airports with non-zero lambdas. Five of them are smallsized: Algeciras (a heliport that is a reference for three airports), Logroño (3), Madrid Cuatro Vientos (19), Vitoria (2) and Zaragoza (26) in the mainland and La Gomera (11), in the Canary Islands. The other benchmarks are all the large airports located in the islands: Gran Canaria (4), Ibiza (10) and 
Palma de Mallorca (13). The relevance of a benchmark for a specific inefficient airport is identified by the value of lambda. For example, Algeciras is a clear reference for El Hierro (lambda=0.8985) and San Sebastian (0.8393), but not for Ceuta (0.0759) in spite of the latter being also a heliport. Note also that, although Ibiza is a benchmark for many inefficient airports, its relevance is very low $(0.01$ to 0.13 ).

The size and location of efficient airports that are not benchmarks to inefficient airports are diverse. There are five large airports two of them located in the Mediterranean seaside (Alicante and Barcelona), a hub in the centre (Madrid Barajas) and two airports in the Canary Islands (Lanzarote and Tenerife South). There is also one medium airport, Murcia (in the Mediterranean corridor) and six small airports geographically dispersed: Albacete, Badajoz, and Burgos; including three of the four general aviation airports (Madrid Torrejon, Sabadell and Son Bonet). Regarding the fact that both Barcelona and Madrid are not benchmarks for any airport other than themselves suggest that they are mavericks that do not have an influence on the rest of the system as regards efficiency. Therefore, in this case, the methodology does not seem to be affected by the presence of extreme cases in inputs and outputs potentially biasing the efficiency frontier as may happen in general in DEA.

Madrid Cuatro Vientos and Zaragoza are benchmarks with relatively high lambdas for a relatively high number of inefficient airports. In particular, Madrid Cuatro Vientos the main reference to some airports with a low number of passengers such as Almeria (lambda $=0.84$ ), Salamanca (0.83), Ceuta (0.76), Jerez (0.67), Huesca-Pirineos(0.57) and Vigo(0.45). Madrid Cuatro Vientos is a general aviation airport, which suggests that specialisation and diversification of activities could help civilian airports to improve the efficiency levels. Zaragoza, on the other hand, is a cargo-oriented airport that acts as the main reference for 15 inefficient airports, with lambdas values ranging between 0.42 (Bilbao) and 0.91 (Leon). These airports are relatively similar in labour and operating costs as well as in some of the outputs except cargo. These results confirm that cargo-activities should be reconsidered by AENA to enhance the overall efficiency of the airport system. Vitoria is also a cargooriented airport but is not such an important reference as Zaragoza for neither Bilbao (0.2361) nor for El Hierro (0.2277).

Malaga, which as indicated above has significant input and outputs slacks, has Palma de Mallorca as its main reference (0.86) Both airports are very similar as regards their commercial revenues, flights on time, labour and operating costs. Nevertheless, the depreciation in the case of Malaga is almost four times than of Palma de Mallorca. Although both airports have very similar runways (i.e. same area), Malaga's new terminal has a significantly higher capacity compared to Palma de Mallorca. Malaga's lower traffic explains its over-capacity and higher capital cost burdening this airport. Thus, while the number of passengers of Malaga airport represents $57 \%$ of that of Palma de Mallorca, the aircraft movements $60 \%$ and cargo just $22 \%$ both have similar labour costs (Malaga airport $88 \%$ of those of Palma), suggesting a high degree of over-employment to run and maintain Malaga's airport premises. The results show clear evidence of the impact of wrong investment decisions (overly optimistic traffic forecasts) in airports' efficiency. Additionally, a potential impact in their financial results: it is not unreasonable to expect Malaga to be no-profitable due to having so many input and output slacks.

The results of the proposed centralised DEA model provide targets for each airport in order to improve the overall efficiency of the network. It is not surprising that the largest system slack occurs in cargo activities. Although the system also requires increasing the number of total passengers (8.62\%), aircraft movements (11.68\%) and commercial revenues (3.08\%), these are significantly lower than the increase required in handling (142.10\%). In order to gain insight into these results, a sensitivity analysis has been performed by removing the two cargo-oriented efficient airports (Vitoria and Zaragoza) from the sample. In that case, the results of Step I identifies Tenerife North as an additional efficient airport. Figure 1 shows the total input and output slacks computed by the centralised DEA model when the cargo-oriented airports are removed from the sample. Note that the total cargo slack is significantly smaller ( $11.59 \%$ compared to $142.10 \%$ of the whole dataset case) 
which means that the cargo targets for the inefficient DMUs are less ambitious, but more realistic to achieve in the short-term. These findings suggest that Vitoria and Zaragoza may be distorting the cargo requirements for the rest of the airports to become efficient. As regards the other variables, more labour costs and aircraft movement slacks and less passengers slack are estimated. For commercial revenues and percentage of flights on time the total slacks do not change much. In summary, removing these two cargo-oriented airports (which may be thought of as outliers) from the sample leads to more sensible targets in the sense that, as one of the reviewers pointed out, airports do not have much control over the demand for cargo and passengers services and therefore identifying large scopes for improving cargo and passengers may be an unrealistic source of inefficiency.

Figure 1: Total input and output slacks when Vitoria and Zaragoza are excluded from the dataset

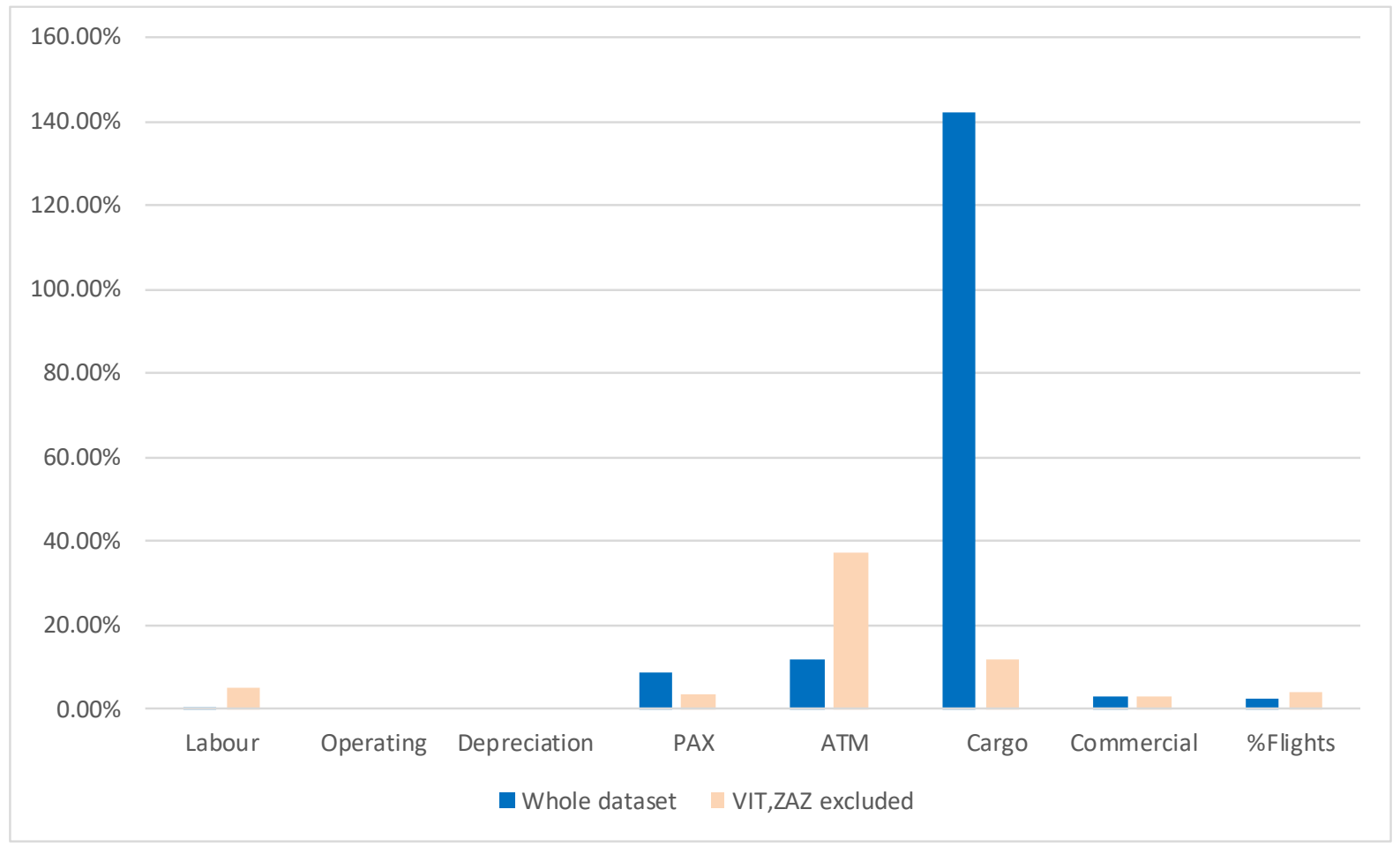

\section{Size and organizational inefficiency analysis}

The analysis carried out in the previous section involved some constraints (namely maintaining the output levels of the individual airports and reallocating resources only among the inefficient airports) that were imposed due to practical management considerations. In this section, the effects of removing those constraints are studied. Moreover, the size inefficiency of the individual airports (see Maindiratta 1990, Ray and Mukherjee 1998, Ray 2007) and of the whole organization, i.e. the whole airport industry (see Ray and Hu 1997, Peyrache 2013, Peyrache and Zago 2016) are also assessed. The corresponding DEA models are shown in Appendix A.

Table 5 shows the potential efficiency improvement (i.e. the SBI efficiency score) of each individual airport computed using model (5) together with the potential efficiency improvement if we allow each airport to be broken up in smaller airports that together would maintain (or even increase) the output level at the same time that resource consumption is reduced. The difference between these two SBI efficiency scores is a measure of the size inefficiency of each individual airport. The number of units in which each size inefficient airports could be split is also shown. Efficient airports are shown in italics and size efficient airports are shown in bold. Note that all efficient airports (including Barcelona and Madrid Barajas) are also size efficient while there are 
some size efficient airports (namely Ceuta, El Hierro, Huesca-Pirineos, Salamanca and San Sebastian) that are technical inefficient. Malaga and Sevilla are the airports with the largest size inefficiencies leading to gains if they were broken into nine and eight units, respectively. These two airports correspond to the largest cities in the Andalusian region and hence concentrate most of the traffic in the region.

Table 5: Individual airports size efficiency and resulting number of units from their break up

\begin{tabular}{|c|c|c|c|c|}
\hline Airport & SBI Value & Break up SBI & Size inefficiency & \# units \\
\hline A Coruña & 0.0087 & 0.0142 & 0.0055 & 5 \\
\hline Albacete & 0.0000 & 0.0000 & 0.0000 & 1 \\
\hline Algeciras & 0.0000 & 0.0000 & 0.0000 & 1 \\
\hline Alicante & 0.0000 & 0.0000 & 0.0000 & 1 \\
\hline Almeria & 0.0047 & 0.0111 & 0.0063 & 4 \\
\hline Asturias & 0.0080 & 0.0165 & 0.0084 & 6 \\
\hline Badajoz & 0.0000 & 0.0000 & 0.0000 & 1 \\
\hline Barcelona & 0.0000 & 0.0000 & 0.0000 & 1 \\
\hline Bilbao & 0.0074 & 0.0080 & 0.0006 & 3 \\
\hline Burgos & 0.0000 & 0.0000 & 0.0000 & 1 \\
\hline Ceuta & 0.0009 & 0.0008 & 0.0000 & 1 \\
\hline Cordoba & 0.0024 & 0.0034 & 0.0010 & 2 \\
\hline El Hierro & 0.0005 & 0.0005 & 0.0000 & 1 \\
\hline Fuerteventura & 0.0089 & 0.0094 & 0.0005 & 3 \\
\hline Girona & 0.0091 & 0.0102 & 0.0010 & 4 \\
\hline Gran Canaria & 0.0000 & 0.0000 & 0.0000 & 1 \\
\hline Granada-Jaen & 0.0117 & 0.0170 & 0.0052 & 6 \\
\hline Huesca-Pirineos & 0.0011 & 0.0011 & 0.0000 & 1 \\
\hline Ibiza & 0.0000 & 0.0000 & 0.0000 & 1 \\
\hline Jerez & 0.0026 & 0.0099 & 0.0073 & 4 \\
\hline La Gomera & 0.0000 & 0.0000 & 0.0000 & 1 \\
\hline La Palma & 0.0113 & 0.0175 & 0.0062 & 6 \\
\hline Lanzarote & 0.0000 & 0.0000 & 0.0000 & 1 \\
\hline Leon & 0.0025 & 0.0036 & 0.0011 & 2 \\
\hline Logroño & 0.0000 & 0.0000 & 0.0000 & 1 \\
\hline Madrid Barajas & 0.0000 & 0.0000 & 0.0000 & 1 \\
\hline $\begin{array}{l}\text { Madrid Cuatro } \\
\text { Vientos }\end{array}$ & 0.0000 & 0.0000 & 0.0000 & 1 \\
\hline Madrid Torrejon & 0.0000 & 0.0000 & 0.0000 & 1 \\
\hline Malaga & 0.0170 & 0.0378 & 0.0207 & 9 \\
\hline Melilla & 0.0071 & 0.0093 & 0.0022 & 3 \\
\hline Menorca & 0.0158 & 0.0276 & 0.0117 & 10 \\
\hline Murcia & 0.0000 & 0.0000 & 0.0000 & 1 \\
\hline Palma de Mallorca & 0.0000 & 0.0000 & 0.0000 & 1 \\
\hline
\end{tabular}




\begin{tabular}{lllll}
\hline Pamplona & 0.0104 & 0.0121 & 0.0016 & 4 \\
\hline Reus & 0.0092 & 0.0137 & 0.0045 & 5 \\
\hline Sabadell & $\mathbf{0 . 0 0 0 0}$ & $\mathbf{0 . 0 0 0 0}$ & $\mathbf{0 . 0 0 0 0}$ & $\mathbf{1}$ \\
\hline Salamanca & $\mathbf{0 . 0 0 1 3}$ & $\mathbf{0 . 0 0 1 3}$ & $\mathbf{0 . 0 0 0 0}$ & $\mathbf{1}$ \\
\hline San Sebastian & $\mathbf{0 . 0 0 1 2}$ & $\mathbf{0 . 0 0 1 1}$ & -0.0001 & $\mathbf{1}$ \\
\hline Santander & 0.0029 & 0.0046 & 0.0017 & 2 \\
\hline Santiago & 0.0171 & 0.0273 & 0.0102 & 9 \\
\hline Sevilla & 0.0056 & 0.0212 & 0.0156 & 8 \\
\hline Son Bonet & $\mathbf{0 . 0 0 0 0}$ & $\mathbf{0 . 0 0 0 0}$ & $\mathbf{0 . 0 0 0 0}$ & $\mathbf{1}$ \\
\hline Tenerife North & 0.0071 & 0.0183 & 0.0111 & 6 \\
\hline Tenerife South & $\mathbf{0 . 0 0 0 0}$ & $\mathbf{0 . 0 0 0 0}$ & $\mathbf{0 . 0 0 0 0}$ & $\mathbf{1}$ \\
\hline Valencia & 0.0047 & 0.0106 & 0.0058 & 4 \\
\hline Valladolid & 0.0085 & 0.0113 & 0.0028 & 3 \\
\hline Vigo & 0.0091 & 0.0167 & 0.0076 & 6 \\
\hline Vitoria & $\mathbf{0 . 0 0 0 0}$ & $\mathbf{0 . 0 0 0 0}$ & $\mathbf{0 . 0 0 0 0}$ & $\mathbf{1}$ \\
\hline Zaragoza & $\mathbf{0 . 0 0 0 0}$ & $\mathbf{0 . 0 0 0 0}$ & $\mathbf{0 . 0 0 0 0}$ & $\mathbf{1}$ \\
\hline
\end{tabular}

The first row in Table 6 shows the sum of the potential improvements if the technical inefficiency of the individual airports is removed using the non-centralized approach, i.e. solving model (5). The second row shows the potential system gains if only the inefficient airports are considered for resource reallocation, i.e. solving model (6). The third row corresponds to also including the efficient airports in the resource reallocation, i.e. solving model (9) in Appendix A. Finally, the last row shows the potential efficiency gains if the constraints maintaining the output levels of the individual airports are removed, i.e. solving model (10) in Appendix A. It can be seen that in every of these progressively more relaxed scenarios the overall potential efficiency gain (as measured by the corresponding SBI score) increases. Note that while the non-centralized approach detected inefficiencies in the inputs (mainly in Labour) the centralized approach reallocates those resources within the system so that there is not so much excess. However, the additional gains in efficiency that are achieved in the case of the output level constraints are relaxed leads to some excess in the Labour input.

Table 6: Total system efficiency gains of increasing relaxed scenarios

\begin{tabular}{|c|c|c|c|c|c|c|c|c|}
\hline Scenario & SBI & Labour & Operating & PAX & ATM & Cargo & $\begin{array}{l}\text { Commer. } \\
\text { revenues }\end{array}$ & $\begin{array}{c}\text { \% Flights on } \\
\text { Time }\end{array}$ \\
\hline Non-centralised & 0.1970 & $5.82 \%$ & $0.57 \%$ & $3.12 \%$ & $7.45 \%$ & $110.93 \%$ & $1.71 \%$ & $2.47 \%$ \\
\hline $\begin{array}{l}\text { Centralised } \\
\text { inefficient } \\
\text { airports }\end{array}$ & 0.2474 & $0.12 \%$ & $0.00 \%$ & $8.62 \%$ & $11.68 \%$ & $142.10 \%$ & $3.08 \%$ & $2.24 \%$ \\
\hline $\begin{array}{l}\text { Centralised all } \\
\text { airports }\end{array}$ & 0.2907 & $0.00 \%$ & $0.00 \%$ & $6.82 \%$ & $3.69 \%$ & $184.51 \%$ & $2.84 \%$ & $1.37 \%$ \\
\hline $\begin{array}{l}\text { Centralised } \\
\text { unconstrained } \\
\text { output levels }\end{array}$ & 0.3617 & $2.05 \%$ & $0.00 \%$ & $5.53 \%$ & $26.18 \%$ & $216.94 \%$ & $0.00 \%$ & $2.04 \%$ \\
\hline
\end{tabular}

Finally, the overall size efficiency of the company (AENA) can be assessed allowing for a hypothetical restructuring of the system so that the same level of the outputs (or even larger ones) can be obtained with lower resources levels consumed by an optimal number of airports operating 
at an optimal size (Ray and Hu 1997, Peyrache 2013). This corresponds to solving model (8) in Appendix A. The optimal number of units in which the system might break up is 207, with a potential efficiency gain of 33.32. (measured by the SBI efficiency score with respect to the corresponding industry technology). Note that the potential efficiency gains of such a radical restructuring are much higher than those that can be obtained in the different scenarios considered in Table 6. Table 7 shows the inputs and outputs of the optimal size operating point. The comparison of the corresponding inputs and outputs of the existing airports with this optimal size operating point is shown in Table B. 3 in Appendix B, with a " + " entry meaning that the input or output value of the corresponding airport is larger than that of the optimal size operating point and the opposite if the entry is "-". Note that most airports are above the optimal size in terms of the inputs while most are below the optimal size in terms of the outputs. Large airports (e.g. Madrid or Barcelona) are above the optimal size in all variables except in the percentage of flights on time, in which they are below. Some airports (e.g. Malaga, Ibiza or Lanzarote) are above the optimal size in all variables except in the percentage of flights on time and in cargo. This is because most of the traffic of those airports is driven by tourism. On the contrary, Vitoria and Zaragoza are above the optimal size as regards cargo but they are below in passengers and movements (as well as in commercial revenues).

Table 7: Optimal size operating point

\begin{tabular}{|l|r|}
\hline Labour & $1,447.26$ \\
\hline Operating & $4,505.87$ \\
\hline Deprec. & 978.31 \\
\hline PAX & $905,338.79$ \\
\hline ATM & $8,651.92$ \\
\hline Cargo & $3,086,730.06$ \\
\hline Comm. revenues & $3,045.43$ \\
\hline \% Flights on Time & 50.00 \\
\hline
\end{tabular}

\section{Conclusions}

In this study we evaluate the efficiency level of the Spanish airports centralised managed under the same government agency (AENA). The proposed approach uses firstly a conventional (i.e. noncentralised DEA) non-oriented SBI model to identify the efficient and the inefficient airports. Then a centralised DEA approach is used to compute input and output targets for each the inefficient airports looking for the overall improvement of the system performance. The results show that out of the 49 airports studied 21 airports (of different sizes) are technically efficient. Hence, not always larger airports are more efficient compared to medium and small airports that may be using better their resources for the level of traffic they have. These results confront previous findings in the Spanish airports where airports with more passengers are more technically efficient. Overall the proposed approach estimates that the system requires more aircraft movements and handling increases than increases in the number of passengers. The labour costs are adequate for the current activity. The overall margin of improvement as regards punctuality is very small, suggesting that most of that airports are punctual and do not suffer from significant delays.

The efficient frontier does not change much when the two cargo-oriented airports (Vitoria and Zaragoza) are removed from the sample, with just one new airport, Tenerife North, becoming technical efficient. The cargo target computed in that case is, however, much lower and, hence, easier to reach in the short-term. The aircraft movements, however, would still have to be increased, actually more than before. Overall, removing these two cargo-oriented airports leads to more a realistic assessment of the margin for improvement as regards the cargo output. 
The proposed centralised DEA approach clearly shows an individual pathway for each airport to contribute to increasing the overall efficiency of the system, carrying out an improved reallocation of the available resources. It has been found that the results are not biased by the existence of exceptional observations (i.e. observations with much large inputs and outputs than the rest) as it may happen in DEA. Previous studies have also applied DEA models, but their results do not provide a clear indication of which resources should be reduced or perhaps increased in each airport. But, they may provide an overall reduction of the inputs (input-oriented) or an overall increase of the outputs (output-oriented). Additionally, airports are treated as decision making units assuming that the consumption of inputs and production targets are decided by airports' managers. As previously discussed the existing Spanish regulatory framework makes this unlikely to happen under a strong centralised management.

Although airports are treated as public utilities and the Spanish government insists on keeping all the airports open to aeronautical activities. The fixed costs of this policy seem not to have been factored in the analysis. Overall, the employment level is adequate for the actual traffic. Nevertheless, this does not apply to certain outputs, as implied by the fact that 28 out of 49 airports being technically inefficient. From an accounting perspective and assuming that all the efficient airports are able to cover their fixed costs and become profitable, the2 1 efficient airports are financially sustaining the whole system. The question to be addressed is if the inefficient airports (and potentially not profitable) are strictly required for example ensuring connectivity. For example, the island airports may remain open even being a financial burden for the system. Previous studies mention certain externalities that could enhance the efficiency of some airports in detriment of others, such as the geographical location. Nevertheless, the results found in this study indicate that, at least in the Spanish case, passengers are not as essential as attracting airlines (air traffic movements) and increasing cargo. Some airports are suffering from over-capacity due to the significant investments in infrastructure carried out have not been followed by an increase in traffic of the same order. Another finding of this study is that airports' specialisation helps increasing the overall efficiency of the system. Previous studies have confirmed the contribution to the financial aspect of the system (Ripoll-Zarraga and Mar Molinero, 2017 and Ripoll-Zarraga et al. 2017). This is only possible if airports provide a better quality of the services provided to make the Spanish airports attractive for opening new routes. Consequently, airports must be differentiated regarding the product offered and must compete with each other. The current strong centralised management may make these targets hard to achieve. Airports' managers need to be granted the power to decide price policies and negotiate directly with specific airlines, opening new routes and making secondary airports as airlines hubs.

As regards the size efficiency of the individual airports it has been found that all efficient airports (including Barcelona and Madrid Barajas) are also size efficient, that there are some size efficient airports that are technical inefficient and that Malaga and Sevilla are the airports with the largest size inefficiencies. The sum of the potential improvements for progressively more relaxed scenarios has also been computed. These scenarios correspond to 1) non-centralized approach, 2) centralised approach where only the inefficient airports are considered for resource reallocation, 3) centralised approach where efficient airports are also considered for resource reallocation, 4) centralised approach where all airports are considered for resource reallocation and the constraints maintaining the output levels of the individual airports are removed. It has been found that the overall potential efficiency gains increase when we move from one scenario to the next and that the non-centralized approach detects more inefficiencies in the inputs (mainly in Labour) than the centralized approach, which can productively reallocate those resources within the system and increase the total outputs.

The overall size efficiency of the company (AENA) has also been assessed and the optimal number of airports and their optimal size has been determined. This has allowed comparing the inputs and outputs of the existing airports with those of the optimal size operating point. It has been found that, in general, most Spanish airports are above the optimal size in terms of the inputs while they are below the optimal size in terms of the outputs. Thus, for example, large airports (e.g. Madrid or 
Barcelona) are above the optimal size in all variables except in the percentage of flights on time while tourism-oriented airports (e.g. Malaga, Ibiza or Lanzarote) are above the optimal size in all variables except in the percentage of flights on time and in cargo.

As continuation of this research, one possibility is the one suggested by one of the reviewers and consists in allowing the possibility of output reallocation like, for example, transferring cargo from busy airports to other airports with excess capacity (moving the cargo on roads). Those transfers should be assigned costs and an approach analogous to that of Pachkova (2009) may be developed. Another interesting topic is that of charting a long-term path from the current situation to a desirable one with the optimal number and size of airports. This would involve breaking up size inefficient airports, closing some airports and merging others. The DEA estimated gains from such a restructuring seem to be significant but the restructuring costs should also be factored in.

\section{Acknowledgements}

This research was carried out with the financial support of the Spanish Ministry of Science and the European Regional Development Fund (ERDF), grant DPI2017-85343-P. The authors are also grateful to two anonymous reviewers and the Guest Editor for their constructive remarks and suggestions, which were very helpful for improving the paper.

\section{Appendix A}

Size inefficiency of individual airports model

$S B I_{o}=\operatorname{Max} \frac{1}{\left|I^{D}\right|+|O|} \cdot\left(\sum_{i \in I^{D}} \frac{s_{i o}^{x}}{g_{i}^{x}}+\sum_{k \in O} \frac{s_{k o}^{y}}{g_{k}^{y}}\right)$

s.t.

$\sum_{j=1}^{n} \lambda_{j} x_{i j}=x_{i o}-s_{i o}^{x} \quad \forall i \in I^{D}$

$\sum_{j=1}^{n} \lambda_{j} x_{i j} \leq x_{i o} \quad \forall i \in I^{N D}$

$\sum_{j=1}^{n} \lambda_{j} y_{k j}=y_{k o}+s_{k o}^{y} \quad \forall k \in O$

$\sum_{j=1}^{n} \lambda_{j}=m$

$\lambda_{j} \geq 0 \forall j \quad s_{i o}^{x} \geq 0 \quad \forall i \in I^{N D} \quad s_{k o}^{y} \geq 0 \quad \forall k \in O \quad m \in \square$

\section{$\underline{\text { Size inefficiency of airport industry model }}$}

$S B I=\operatorname{Max} \frac{1}{\left|I^{D}\right|+|O|} \cdot\left(\sum_{i \in I^{D}} \frac{S_{i}^{x}}{g_{i}^{x}}+\sum_{k \in O} \frac{S_{k}^{y}}{g_{k}^{y}}\right)$

s.t.

$\sum_{j=1}^{n} \lambda_{j} x_{i j}=\sum_{r=1}^{n} x_{i r}-S_{i}^{x} \quad \forall i \in I^{D}$ 


$$
\begin{aligned}
& \sum_{j=1}^{n} \lambda_{j} x_{i j} \leq \sum_{r=1}^{n} x_{i r} \quad \forall i \in I^{N D} \\
& \sum_{j=1}^{n} \lambda_{j} y_{k j}=\sum_{r=1}^{n} y_{k r}+S_{k}^{y} \quad \forall k \in O \\
& \sum_{j=1}^{n} \lambda_{j}=m \\
& \lambda_{j} \geq 0 \quad \forall j \quad S_{i}^{x} \geq 0 \quad \forall i \in I^{D} \quad S_{k}^{y} \geq 0 \quad \forall k \in O \quad m \in \square
\end{aligned}
$$

\section{Centralised all airports model}

$$
S B I_{o}=\operatorname{Max} \frac{1}{\left|I^{D}\right|+|O|} \cdot\left(\sum_{i \in I^{D}} \frac{S_{i}^{x}}{g_{i}^{x}}+\sum_{k \in O} \frac{S_{k}^{y}}{g_{k}^{y}}\right)
$$

s.t.

$\sum_{j \in E} \lambda_{j r} x_{i j} \leq \hat{x}_{i r} \quad \forall i \in I^{D} \forall r$

$\sum_{r=1}^{n} \hat{x}_{i r}=\sum_{r=1}^{n} x_{i r}-S_{i}^{x} \quad \forall i \in I^{D}$

$\sum_{j=1}^{n} \lambda_{j r} x_{i j} \leq x_{i r} \quad \forall i \in I^{N D} \forall r$

$\sum_{j \in E} \lambda_{j r} y_{k j} \geq \hat{y}_{k r} \geq y_{k r} \quad \forall k \in O \forall r$

$\sum_{r=1}^{n} \hat{y}_{k r}=\sum_{r=1}^{n} y_{k r}+S_{k}^{y} \quad \forall k \in O$

$\sum_{j \in E} \lambda_{j r}=1 \quad \forall r$

$\lambda_{j r} \geq 0 \quad \forall j \in E \forall r \quad S_{i}^{x} \geq 0 \quad \forall i \in I^{D} \quad S_{k}^{y} \geq 0 \quad \forall k \in O$

\section{Centralised unconstrained output levels model}

$$
S B I_{o}=\operatorname{Max} \frac{1}{\left|I^{D}\right|+|O|} \cdot\left(\sum_{i \in I^{D}} \frac{S_{i}^{x}}{g_{i}^{x}}+\sum_{k \in O} \frac{S_{k}^{y}}{g_{k}^{y}}\right)
$$

s.t.

$\sum_{j \in E} \lambda_{j r} x_{i j} \leq \hat{x}_{i r} \quad \forall i \in I^{D} \forall r$

$\sum_{r=1}^{n} \hat{x}_{i r}=\sum_{r=1}^{n} x_{i r}-S_{i}^{x} \quad \forall i \in I^{D}$

$\sum_{j=1}^{n} \lambda_{j r} x_{i j} \leq x_{i r} \quad \forall i \in I^{N D} \forall r$

$\sum_{j \in E} \lambda_{j r} y_{k j} \geq \hat{y}_{k r} \quad \forall k \in O \forall r$ 


$$
\begin{aligned}
& \sum_{r=1}^{n} \hat{y}_{k r}=\sum_{r=1}^{n} y_{k r}+S_{k}^{y} \quad \forall k \in O \\
& \sum_{j \in E} \lambda_{j r}=1 \quad \forall r \\
& \lambda_{j r} \geq 0 \quad \forall j \in E \forall r \quad S_{i}^{x} \geq 0 \quad \forall i \in I^{D} \quad S_{k}^{y} \geq 0 \quad \forall k \in O
\end{aligned}
$$

\begin{tabular}{|c|c|c|c|c|c|c|c|}
\hline Airports & Labour & Operating & PAX & ATM & Cargo & $\begin{array}{l}\text { Commer. } \\
\text { revenues }\end{array}$ & $\begin{array}{c}\text { \% Flights } \\
\text { on Time }\end{array}$ \\
\hline A Coruña & -506 & 0 & 0 & 11,428 & $31,243,240$ & 292 & 7.8 \\
\hline Almeria & -948 & 0 & 0 & 24,408 & $9,346,526$ & 0 & 4.1 \\
\hline Asturias & $-1,188$ & 0 & 0 & 16,954 & $27,227,960$ & 176 & 0 \\
\hline Bilbao & 0 & 0 & 939,986 & 0 & $29,323,100$ & 0 & 1.7 \\
\hline Ceuta & 0 & 0 & 8,592 & 2,332 & $1,839,103$ & 80 & 3.9 \\
\hline Cordoba & 0 & 0 & 61,502 & 0 & $10,296,360$ & 179 & 1.0 \\
\hline El Hierro & -539 & -395.11 & 0 & 905 & 0 & 226 & 1.5 \\
\hline Fuerteventura & 0 & 0 & 41,969 & 0 & $36,060,840$ & 0 & 14.0 \\
\hline Girona & 0 & 0 & 0 & 0 & $39,128,790$ & 15 & 6.7 \\
\hline Granada-Jaen & -368 & 0 & 0 & 5,700 & $45,440,820$ & 579 & 13.9 \\
\hline Huesca-Pirineos & 0 & 0 & 25,265 & 0 & $3,620,766$ & 22 & 4.4 \\
\hline Jerez & $-1,037$ & 0 & 603,218 & 0 & $4,854,956$ & 365 & 7.2 \\
\hline La Palma & -358 & 0 & 0 & 0 & $43,740,470$ & 763 & 20.3 \\
\hline Leon & -97 & 0 & 23,939 & 6,924 & $7,804,067$ & 515 & 0 \\
\hline Malaga & $-3,350$ & 0 & $1,771,797$ & 12,934 & $58,253,670$ & 0 & 0 \\
\hline Melilla & 0 & -869.01 & 0 & 12,391 & $21,359,290$ & 939 & 15.9 \\
\hline Menorca & $-1,651$ & 0 & 178,026 & 0 & $65,560,040$ & 820 & 0.7 \\
\hline Pamplona & 0 & -118.47 & 113,403 & 0 & $42,457,260$ & 247 & 12.9 \\
\hline Reus & -413 & 0 & 0 & 9,573 & $32,834,400$ & 446 & 12.9 \\
\hline Salamanca & 0 & $-1,506.64$ & 0 & 2,472 & $2,129,210$ & 90 & 6.7 \\
\hline San Sebastian & -992 & -624.10 & 58,234 & 3,058 & 96,889 & 0 & 5.0 \\
\hline Santander & -943 & 0 & 0 & 0 & $10,426,390$ & 629 & 0 \\
\hline Santiago & $-1,288$ & 0 & 0 & 1,354 & $71,795,950$ & 410 & 4.5 \\
\hline Sevilla & $-2,320$ & 0 & 0 & 3,217 & $16,146,670$ & 0 & 10.8 \\
\hline Tenerife North & -574 & 0 & $1,112,040$ & 0 & $20,937,370$ & 3,414 & 9.3 \\
\hline Valencia & 0 & 0 & 915,375 & 0 & $17,703,540$ & 0 & 1.3 \\
\hline Valladolid & 0 & $-1,761.33$ & 0 & 6,162 & $31,233,570$ & 369 & 10.9 \\
\hline \multirow[t]{2}{*}{ Vigo } & -868 & 0 & 0 & 13,641 & $27,916,230$ & 215 & 21.8 \\
\hline & $-17,439.74$ & $-5,274.66$ & $5,853,348$ & 133,453 & $708,777,477$ & 10,791 & $2.47^{a}$ \\
\hline
\end{tabular}

\section{Appendix B}

Table B.1: Input and output slacks computed by the non-centralised DEA model

\footnotetext{
${ }^{a}$ Weighted average
} 
Table B.2: Peer group and lambda values for the inefficient airports

\begin{tabular}{|c|c|c|c|c|c|c|c|c|c|}
\hline Airport & Algeciras & Gran Canaria & Ibiza & La Gomera & Logroño & Madrid Cuatro Vientos & Palma de Mallorca & Vitoria & Zaragoza \\
\hline A Coruña & 0 & 0 & 0.1100 & 0.3626 & 0 & 0.0886 & 0 & 0 & 0.4388 \\
\hline Almeria & 0 & 0.0083 & 0 & 0 & 0 & 0.8439 & 0.0249 & 0 & 0.1229 \\
\hline Asturias & 0 & 0 & 0.0912 & 0.1860 & 0 & 0.3238 & 0.0148 & 0 & 0.3843 \\
\hline Bilbao & 0 & 0.1653 & 0 & 0 & 0 & 0.0554 & 0.1201 & 0.2361 & 0.4231 \\
\hline Ceuta & 0.0759 & 0 & 0 & 0.1623 & 0 & 0.7618 & 0 & 0 & 0 \\
\hline Cordoba & 0 & 0 & 0 & 0 & 0.2454 & 0 & 0.0018 & 0.2277 & 0.5251 \\
\hline El Hierro & 0.8985 & 0 & 0.0237 & 0.0237 & 0 & 0.0535 & 0 & 0 & 0.0007 \\
\hline Fuerteventura & 0 & 0 & 0 & 0 & 0 & 0 & 0.1939 & 0 & 0.8061 \\
\hline Girona & 0 & 0 & 0.0604 & 0 & 0 & 0.0708 & 0.0894 & 0 & 0.7794 \\
\hline Granada-Jaen & 0 & 0 & 0.0597 & 0.2513 & 0 & 0.0548 & 0 & 0 & 0.6341 \\
\hline Huesca-Pirineos & 0 & 0 & 0 & 0 & 0 & 0.5686 & 0 & 0 & 0.4314 \\
\hline Jerez & 0 & 0 & 0 & 0 & 0 & 0.6749 & 0.0966 & 0 & 0.2284 \\
\hline Leon & 0 & 0 & 0 & 0 & 0.0842 & 0 & 0 & 0 & 0.9158 \\
\hline Malaga & 0 & 0 & 0 & 0 & 0.1232 & 0 & 0.8571 & 0 & 0.0196 \\
\hline Melilla & 0 & 0 & 0.0244 & 0.5885 & 0 & 0.0917 & 0 & 0 & 0.2954 \\
\hline Menorca & 0 & 0 & 0 & 0 & 0 & 0 & 0.1035 & 0 & 0.8965 \\
\hline Pamplona & 0 & 0 & 0 & 0 & 0 & 0.3491 & 0 & 0 & 0.6509 \\
\hline Reus & 0 & 0 & 0.1314 & 0.2475 & 0 & 0.1580 & 0 & 0 & 0.4631 \\
\hline Salamanca & 0 & 0 & 0 & 0.1474 & 0 & 0.8294 & 0 & 0 & 0.0232 \\
\hline San Sebastian & 0.8393 & 0.0259 & 0 & 0 & 0 & 0.1349 & 0 & 0 & 0 \\
\hline Santander & 0 & 0 & 0.1320 & 0.3057 & 0 & 0.1023 & 0 & 0 & 0.4600 \\
\hline Santiago & 0 & 0 & 0 & 0 & 0 & 0 & 0.0844 & 0 & 0.9156 \\
\hline Sevilla & 0 & 0.2536 & 0 & 0 & 0 & 0.4834 & 0.0488 & 0 & 0.2142 \\
\hline Tenerife North & 0 & 0 & 0 & 0 & 0 & 0 & 0.2565 & 0 & 0.7435 \\
\hline Valencia & 0 & 0 & 0 & 0 & 0 & 0 & 0.3049 & 0 & 0.6951 \\
\hline Valladolid & 0 & 0 & 0.0103 & 0.3966 & 0 & 0.1757 & 0 & 0 & 0.4174 \\
\hline Vigo & 0 & 0 & 0.0865 & 0.0672 & 0 & 0.4515 & 0 & 0 & 0.3948 \\
\hline
\end{tabular}


Table B.3: Comparison of existing airports with the optimal size operating point

\begin{tabular}{|c|c|c|c|c|c|c|c|c|}
\hline Airport & Labour & Operating & Deprec. & PAX & ATM & Cargo & $\begin{array}{l}\text { Comm. } \\
\text { revenues }\end{array}$ & $\begin{array}{c}\text { \% Flights on } \\
\text { Time }\end{array}$ \\
\hline A Coruña & + & - & + & - & + & - & - & - \\
\hline Albacete & - & - & - & - & - & - & - & + \\
\hline Algeciras & - & - & - & - & - & - & - & - \\
\hline Alicante & + & + & + & + & + & - & + & - \\
\hline Almeria & + & + & - & - & + & - & - & + \\
\hline Asturias & + & + & + & + & + & - & - & + \\
\hline Badajoz & - & - & - & - & - & - & - & - \\
\hline Barcelona & + & + & + & + & + & + & + & - \\
\hline Bilbao & + & + & + & + & + & - & + & + \\
\hline Burgos & - & - & + & - & - & - & - & + \\
\hline Ceuta & - & - & - & - & - & - & - & - \\
\hline Cordoba & - & - & + & - & - & - & - & + \\
\hline El Hierro & - & - & - & - & - & - & - & - \\
\hline Fuerteventura & + & + & + & + & + & - & + & - \\
\hline Girona & + & + & + & + & + & - & + & - \\
\hline Gran Canaria & + & + & + & + & + & + & + & - \\
\hline Granada-Jaen & + & + & + & - & + & - & - & - \\
\hline Huesca-Pirineos & - & - & + & - & - & - & - & - \\
\hline Ibiza & + & + & + & + & + & - & + & - \\
\hline Jerez & + & + & + & - & + & - & + & - \\
\hline La Gomera & - & - & - & - & - & - & - & + \\
\hline La Palma & + & + & + & - & + & - & - & - \\
\hline Lanzarote & + & + & - & + & + & - & + & - \\
\hline Leon & - & - & + & - & - & - & - & + \\
\hline Logroño & - & - & - & - & - & - & - & + \\
\hline Madrid Barajas & + & + & + & + & + & + & + & - \\
\hline $\begin{array}{l}\text { Madrid } \\
\text { CuatroVientos }\end{array}$ & - & - & - & - & + & - & - & + \\
\hline Madrid Torrejon & - & - & + & - & - & - & - & - \\
\hline Malaga & + & + & + & + & + & - & + & - \\
\hline Melilla & + & - & - & - & - & - & - & - \\
\hline Menorca & + & + & + & + & + & - & + & - \\
\hline Murcia & + & - & + & + & + & - & + & - \\
\hline $\begin{array}{l}\text { Palma de } \\
\text { Mallorca }\end{array}$ & + & + & + & + & + & + & + & - \\
\hline Pamplona & + & - & + & - & - & - & - & - \\
\hline Reus & + & + & + & + & + & - & - & - \\
\hline Sabadell & - & - & - & - & + & - & - & + \\
\hline Salamanca & - & - & - & - & - & - & - & - \\
\hline
\end{tabular}




\begin{tabular}{|c|c|c|c|c|c|c|c|c|}
\hline San Sebastian & + & - & - & - & - & - & - & - \\
\hline Santander & + & - & + & + & + & - & - & + \\
\hline Santiago & + & + & + & + & + & - & + & - \\
\hline Sevilla & + & + & + & + & + & + & + & - \\
\hline Son Bonet & - & - & + & - & + & - & - & - \\
\hline Tenerife North & + & + & + & + & + & + & + & - \\
\hline Tenerife South & + & + & + & + & + & + & + & - \\
\hline Valencia & + & + & + & + & + & + & + & - \\
\hline Valladolid & + & - & + & - & - & - & - & - \\
\hline Vigo & + & + & + & - & + & - & - & - \\
\hline Vitoria & + & - & + & - & - & + & - & + \\
\hline Zaragoza & + & - & + & - & - & + & - & - \\
\hline
\end{tabular}

\section{References}

Abbot, M. and Wu, S. (2002): 'Total Factor Productivity and efficiency of Australian airports' Australian Economic Review 35(3), 244-260

Amirteimoori, A. (2006): 'Data envelopment analysis in dynamic framework' Applied Mathematics and Computation 181 (1), 21-28

Amirteimoori, A. and Emrouznejad, A. (2012): 'Optimal input/output reduction in production processes' Decision Support Systems 52(3), 742-747

Amirteimoori, A. and Shafiei, M. (2006): 'Characterizing an equitable omission of shared resources: a DEA-based approach' Applied Mathematics and Computation177 (1), 18-23

Ashford, N., Stanton, H. and Moore, C. (1996): 'Airport Operations' NewYork, McGraw-Hill Education (second edition)

Asmild, M.; Paradi, J.C. and Pastor, J.T. (2009): 'Centralized resource allocation BCC Models' Omega $37,40-49$

Athanassopoulos, A.D. (1995): 'Goal programming \& Data Envelopment Analysis (GoDEA) for targetbased multi-level planning: allocating central grants to the Greek local authorities' European Journal of Operational Research 87(3), 535-550

Barros, C.P. and Dieke, P.U.C. (2007): 'Performance evaluation of Italian airports: A data envelopment analysis' Journal of Air Transport Management 13, 184-191

Banker, R.D.; Charnes, A. and Cooper, W.W. (1984):'Some models for estimating technical and scale inefficiencies in Data Envelopment Analysis' Management Science 30(9), 1078-1092

Banker, R.D. and Morey, R. (1986):'Efficiency analysis for exogenously fixed inputs and outputs' Operations Research 34, 513-521

Beasley, J.E. (2003) 'Allocating fixed costs and resources via Data Envelopment Analysis' European Journal of Operational Research 147(1), 198-216

Bogetoft, P. (2013): 'Performance benchmarking: Measuring and managing performance' Springer, New York

Boussofiane, A.; Dyson, R.G. and Thanassoulis, E. (1991): 'Applied Data Envelopment Analysis' European Journal of Operational Research 52(1), 1-15 
Cook, W.D.; Tone, K. and Zhu, J. (2014): 'Data Envelopment Analysis: prior to choosing a model' Omega 44, 1-4

Coto-Millan, P.; Inglada, V.; Fernandez, X.L.; Inglada-Perez, L. and Pesquera, M.A. (2016): 'The effect procargo on technical and scale efficiency at airports: The case of Spanish airports (2009-2011)' Utilities Policy 39, 29-35

Du, J.; Liang, L.; Chen, Y. and Gon-bing, B. (2010): 'DEA-based production planning' Omega 38 (1-2), 105-112

Fang, L. (2013): 'A generalized DEA model for centralized resource allocation' European Journal of Operational Research 228 (2), 405-412

Fang, L. and Li, H. (2015): 'Centralized resource allocation based on the cost-revenue analysis' Computers \& Industrial Engineering 85, 395-401

Färe, R.; Grosskopf, S.; Kerstens, K.; Kirkley, J.E. and Squires, D. (2000): 'Assessing short-run and medium-run fishing capacity at the industry level and its reallocation' Microbehaviour and Macroresults: Proceedings of the Tenth Biennial Conference of the International Institute of Fisheries Economics and Trade (IIFET), July 10-14 (2000) Corvallis, Oregon, USA

Fukuyama, H. and Weber, W.L. (2009): A directional slacks-based measure of technical inefficiency, Socio-Economic Planning Sciences 43, 274-287

Fukuyama, H. and Weber, W.L. (2010):'A slacks-based inefficiency measure for a two-stage system with bad outputs' Omega 38(5), 398-409

Gillen, D. and Lall, A. (1997): 'Developing measures of airport productivity and performance: an application of data envelopment analysis' Transportation Research-E 33 (4), 261-273

Gimenez-Garcia, V.; Martinez-Parra, J.L. and Buffa, F.P. (2007): 'Improving resource utilisation in multi-unit networked organisations: the case of a Spanish restaurant chain' Tourism Management $28,262-270$

Gutierrez, E. and Lozano, S. (2016): 'Efficiency assessment and output maximization possibilities of European small and medium sized airports' Research in Transportation Economics 56, 3-14

Gutierrez, E.; Aguilera, E.; Lozano, S. and Guzman, G.I. (2017): 'A two-stage DEA approach for quantifying and analysing the inefficiency of conventional and organic rain-fed cereals in Spain' Journal of Cleaner Production 149, 335-348

Hadi-Vencheh, A.; Foroughi Ali, A. and Soleimani-Damaneh, M. (2008): 'A DEA model for resource allocation' Economic Modelling 25 (5), 983-993

Hosseinzadeh Lofti, F.; Noora, A.A.; Jahanshahloo, G.R.; Gerami, J. and Mozaffari, M.R. (2010): 'Centralized resource allocation for enhanced Russell models' Journal of Computational and Applied Mathematics 235, 1-10

Humphreys, I. (1999): 'Privatisation and commercialisation Changes in UK airport ownerships patterns' Journal of Transport Geography 7, 121-134

Kao, C. (2000): 'Data envelopment analysis in resource allocation: an application to forest management' International Journal of Systems Science 31(9), 1059-1066

Korhonen, P. and Syrjänen, M. (2004): 'Resource allocation based on efficiency analysis' Management Science 50(8), 1134-1144

Li, S.K. and Ng, Y.Ch. (1995): 'Measuring the productive efficiency of a group of firms' International Advances in Economic Research 1(4), 377-390 
Lozano, S. (2016): 'Slacks-based inefficiency approach for general networks with bad outputs: An application to the banking sector' Omega 60, 73-84

Lozano, S. (2017): 'Technical and environmental efficiency of a two-stage production and abatement system' Annals of Operations Research 255, 199-219

Lozano, S. and Villa, G. (2004): 'Centralized resource allocation using Data Envelopment Analysis' Journal of Productivity Analysis 22, 143-161

Lozano, S. and Villa, G. (2005): 'Centralized DEA models with the possibility of downsizing' Journal of the Operational Research Society 56, 357-364

Lozano, S.; Villa, G. and Adenso-Diaz, B. (2004):'Centralized target setting for regional recycling operations using DEA' Omega 32, 101-110

Lozano, S.; Villa, G. and Brännlund, R. (2009): 'Centralised reallocation of emission permits using DEA'. European Journal of Operational Research 193, 752-760

Lozano, S.; Villa, G. and Canca, D. (2011):'Application of centralised DEA approach to capital budgeting in Spanish ports' Computers \& Industrial Engineering 60, 455-465

Lozano, S. and Gutierrez, E. (2011a): 'Efficiency analysis and target setting of Spanish airports' Networks and Spatial Economics 11, 139-157

Lozano, S. and Gutierrez, E. (2011b): 'Slacks-based measure of efficiency of airports with airplanes delays as undesirable outputs' Computers \& Operations Research 38, 131-139

Lozano, S.; Gutierrez, E. and Moreno, P. (2013): 'Network DEA approach to airports performance assessment considering undesirable outputs' Applied Mathematical Modelling 37, 1665-1676

Maindiratta, A. (1990): 'Largest size-efficient scale and size efficiencies of Decision Making Units in Data Envelopment Analysis' Journal of Econometrics 46, 39-56

Mar-Molinero, C.; Prior, D.; Segovia, M.M. and Portillo, F. (2014): 'On centralized resource utilization and its reallocation by using DEA' Annals of Operations Research 221(1), 273-283

Martin, J.C. and Roman, C. (2001): 'An application of DEA to measure the efficiency of Spanish airports' Journal of Air Transportation Management 7,149-157

Martin, J. C. and Roman, C. (2006): 'A benchmarking analysis of Spanish commercial airports. A comparison between SMOP and DEA ranking methods' Networks and Spatial Economics 6, 111-134

Nesterenko, V. andZelenyuk, V. (2007): 'Measuring potential gains from reallocation of resources' Journal of Productivity Analysis 28 (1-2), 107-116

Pachkova, E.V. (2009): 'Restricted reallocation of resources' European Journal of Operational Research 196, 1049-1057

Pathomsiri, S; Haghani, A; Dresner, M. and Windle, R.J. (2008): 'Impact of undesirable outputs on the productivity of US airports' Transportation Research Part E 44, 235-259

Pels, E.; Nijkamp, P. and Rietveld, P. (2003): 'Inefficiency and scale economies of European airports operations' Transportation Research Part E: Logistics and Transportation 39, 341-361

Peyrache, A. (2013): 'Industry structural inefficiency and potential gains from mergers and breakups: a comprehensive approach' European Journal of Operational Research 230, 422-430

Peyrache, A. (2015): 'Cost constrained industry inefficiency' European Journal of Operational Research 247, 996-1002

Peyrache, A. and Zago, A. (2016): 'Large courts, small justice!: the inefficiency and the optimal structure of the Italian justice sector' Omega 64, 42-56 
Ray, S.C. and Hu, X. (1997): 'On the technically efficient organization of an industry: a study of US airlines' Journal of Productivity Analysis 8, 5-18

Ray, S.C. (2007): 'Are some Indian banks too large? An examination of size efficiency in Indian banking' Journal of Productivity Analysis 27, 41-56

Ray, S.C. and Mukherjee, K. (1998): 'A study of size efficiency in US banking: identifying banks that are too large' International Journal of Systems Science 29, 1281-1294

Ripoll-Zarraga, A.E. and Mar-Molinero, C. (2017): 'Spanish airports: a visual study of management efficiency' Funcas Working Papers September, 791 (available online, http://www.funcas.es/publicaciones/Sumario.aspx?ldRef=7-05791, last accessed January 2018)

Ripoll-Zarraga, A.E.; Portillo, F. and Mar-Molinero, C. (2017): 'The impact of the 2008 Economic Crisis in the efficiency of Spanish airports: A DEA Analysis' Funcas Working Papers December, 794 (available online, http://www.funcas.es/publicaciones/Sumario.aspx?ldRef=7-05794, last accessed January 2018)

Sarkis, J. (2000): 'An analysis of the operational efficiency of major airports in the United States' Journal of Operations Management 18, 335-351

Silva Portela M.C.A. (2014): 'Value and quantity data in economic and technical efficiency measurement' Economics Letters 124, 108-112

Tapiador, F.J.; Mateos, A. and Marti-Henneberg, J. (2008): 'The geographical efficiency of Spain's regional airports: a quantitative analysis' Journal of Air Transport Management 14(4), 205-212

Thanassoulis, E. (2001): 'Introduction to the theory and application of Data Envelopment Analysis' Springer, New York

Tone, (2001): 'A slacks-based measure of efficiency in Data Envelopment Analysis'European Journal of Operational Research 130, 498-509

Tovar, B. and Martin-Cejas, R.R. (2010): 'Technical efficiency and productivity changes in Spanish airports: A parametric distance functions approach'. Transportation Research Part E 46(5), 249-260

Varmaz, A.; Varwig, A. and Poddig, T. (2013): 'Centralized resource planning and yardstick competition' Omega 41(1), 112-118

White, S.W. and Bordoloi, S.K. (2015): 'A Review of DEA-based Resource and Cost Allocation models: Implications for services' International Journal of Services and Operations Management 20, 86-101

Wei, Q.L.; Zhang, J. and Zhang, X. (2000): 'An inverse DEA model for input/output estimate' European Journal of Operational Research 121 (1), 151-163

Wu, J.; An, Q.; Ali, S. and Liang, L. (2013): 'DEA based resource allocation considering environmental factors' Mathematical and Computer Modelling 58, 1128-1137

Yan, H.; Wei, Q.L.; Hao, G. (2002): 'DEA models for resource reallocation and production input/output estimation' European Journal of Operational Research 136(1), 19-31

Yu, M.M. (2004): 'Measuring physical efficiency of domestic airports in Taiwan with undesirable outputs and environment factors' Journal of Air Transport Management 10, 295-303

Yu M.M.; Chern, C.C. and Hsiao, B. (2013): 'Human resource rightsizing using centralized data envelopment analysis: Evidence from Taiwan's Airports' Omega 41, 119-130 